Marquette University

e-Publications@Marquette

College of Nursing Faculty Research and

Publications

Nursing, College of

$12-1-2010$

Psychometric Properties of the Arabic Version of the Depressive Cognition Scale in First-Year Adolescent Egyptian Nursing Students

Abir K. Bekhet

Marquette University, abir.bekhet@marquette.edu

Jaclene Zauszniewski

Case Western Reserve University

Accepted version. Journal of Nursing Measurement, Vol. 18, No. 3 (December 2010): 143-152. DOI.

(C) 2010 Springer Publishing Company. Used with permission. 


\section{Psychometric Properties of the Arabic Version of the Depressive Cognition Scale in First-Year Adolescent Egyptian Nursing Students}

Authors: Abir K. Bekhet, PhD, RN, HSMI, Marquette University, Milwaukee, Wisconsin; \& Jaclene A. Zauszniewski, PhD, RN-BC, FAAN, Case Western Reserve University, Cleveland, Ohio

Abstract: Background: Identifying depressive cognitions in adolescent nursing students can be an important step to prevent the development of clinical depression, which is positively associated with suicide. Purpose: This study focused on the psychometric testing of the Arabic version of the Depressive Cognition Scale (A-DCS) among 170 first-year adolescent Egyptian nursing students. Methods: The questionnaire was assessed for internal consistency, homogeneity, and construct validity using factor analysis and convergent validity. Results: Cronbach's alpha for (A-DCS) was .86. The homogeneity of the instrument was supported by item-to-total correlations between .30 and .70. Factor extraction generated only one factor with eigenvalues greater than 1, which is consistent with the English version. The (A-DCS) total score had a strong significant correlation with the Alienation Scale scores $(r=.51, p<.01)$, indicating convergent validity. Conclusion: This scale has the potential to become a useful screening tool for depressive cognitions among Egyptian nursing students.

Suicide is one of three leading causes of death worldwide among 15 to 34 year olds, and its prevalence is increasing significantly among adolescents (Afifi, 2006; Bertolote, Fleishmann, \& Butchart, 2006). Recent data collected from Alexandria, Egypt, showed that $30 \%$ of 1,621 high school adolescents experienced a strong death wish (Afifi, 2006). In fact, depression is a strong predictor to suicide (Afifi, 2006). The evidence has now shown that adolescents not only experience the whole spectrum of mood disorders but also suffer from significant associated morbidity and mortality (Kloos, Collins, Weller, \& Weller, 2007; Son \& Kirchner, 2000). Although frequently unrecognized, depression is common (Son \& Kirchner, 2000). Depression is a potentially fatal disorder; of the 30,000 Americans who commit suicide every year, $90 \%$ have a mental disorder, usually depression (Halter, 2004). Within the next 20 years, depression is predicted to become one of the leading causes of disability worldwide (Badamgarav et al., 2003; Cashman, Hale, Candib, Nimiroski, \& Brookings, 2004). Statistics have shown that depression affects $4 \%-8 \%$ of adolescents (Louters, 2006). Many factors play a role in adolescents'

1 Bekhet \& Zauszniewski 
depression, including genetics, family dysfunction, peer problems, chronic illness, prior depressive episodes, and having a first-degree relative with a history of depression (Carlson, 2000; Castiglia, 2000; Louters, 2006).

In fact, studying depression among adolescents is important especially among the nursing students. Nursing students, the adolescents of today, are the nurses of tomorrow who will deal with human behavior. Their psychological well-being is an important factor in managing their clients' conditions (Bekhet, EIGuenidi, \& Zauszniewski, in press). Healthy nursing students are likely to become healthy nurses who can then model and promote healthy lifestyles with their patients (Ahmadi, Toobaee, \& Alishahi, 2004). A recent study conducted by Ahmadi and colleagues (2004) showed that a significant number of Middle East nursing students were mildly to moderately depressed with feelings of hopelessness (44\%), and some of them had suicidal thoughts. Depression decreases the function of students and disturbs the relationship between the nurse and the patient (Ahmadi, 1994a, 1994b). To decrease depression, the rate of depression should be identified.

A recent qualitative study conducted by Dzurec, Allchin, and Angler (2007) aimed at examining 53 first-year nursing students' reasons for their own or their peers' experiences of feeling down or depressed. Fifty of the responses reflected participants' experiences of feeling down or depressed. The most identified themes were overload, or sense of being overwhelmed, and loneliness or isolation. Similarly, Sax, Bryant, and Gilmartin (2002) demonstrated that the complexity embedded in transitioning to college accounted for depression and feeling down.

A poorly defined problem defies identification and treatment (Müller \& Dzurec, 1993). Although the popular media increasingly reports on the rise of depression among college students, reports of ways to intervene to stem that depression are limited (Dzurec et al., 2007). In fact, detecting and treating early depressive cognition in adolescent nursing students can be an important step in preventing the development of clinical depression and suicide. A growing number of publications in the scientific literature show a great need for clinicians and researchers to have access to reliable and valid research instruments in their own language to measure a concept of interest or concern (Sousa, Zauszniewski, Mendes, \& Zanetti, 2005).

Therefore, a reliable and a valid measure of depressive cognitions that may precede the development of clinical depression and can be used with adolescent Egyptian nursing students is needed. This article reports the psychometric evaluation of the Arabic version of the depressive cognition scale in adolescent Egyptian nursing students.

\section{Instruments to Measure Depression}

2 Bekhet \& Zauszniewski 
There are many instruments that measure the presence and severity of depression, including the Beck Depression Inventory (BDI; Beck, Ward, Mendelson, Mook, \& Erbaugh, 1961), the Hamilton Rating Scale for depression (HRSD; Hamilton, 1960), the Center for Epidemiologic Studies Depression Scale (CES-D; Weissman, Sholomskas, Pottenger, Prusoft, \& Locke, 1977), and the Zung Self-Rating Depression Scale (ZSDS; Zung, 1965). All these instruments are useful in measuring the affective, cognitive, behavioral, and physiological symptoms of depression (Zauszniewski, 1995). However, these instruments do not focus on specific cognitions that may precede the development of clinical depression (Lustman, Clouse, \& Carney, 1988; Lustman, Freedland, Carney, Hong, \& Clouse, 1992; Lustman, Griffith, Gavard, \& Clouse, 1992; Zauszniewski, 1995). In response to this need, Zauszniewski (1995) developed the Depressive Cognition Scale (DCS), which focuses specifically on the measurement of cognitive symptoms that precede the development of clinical depression.

\section{The Depressive Cognition Scale (DCS)}

The conceptual bases of the DCS were Beck's cognitive theory of depression and Erikson's theory of psychosocial development (Zauszniewski, 1995). The DCS assesses eight depressive cognitions that may stem from less than successful progression through developmental stages (Zauszniewski, 1995). These eight depressive cognitions are hopelessness, helplessness, powerlessness, purposelessness, worthlessness, loneliness, emptiness, and meaninglessness (Zauszniewski, 1995). The DCS is a paper-based, selfadministered, 8-item scale scored on a 6-point Likert-type scale ranging from $0=$ Strongly Disagree to 5 = Strongly Agree. Each item in the scale represents one positive cognition. Sample items of the scale include the following: "I think my life is pretty full," and "I'm hopeful about my future." Strong disagreement with the statement of each item of the scale indicates the presence of that specific depressive cognition.

The composite score of the scale ranges from 0 to 40 . Because all items are phrased in a positive direction, they must be reverse scored so that a higher composite score indicates more depressive cognitions (Zauszniewski, 1995). Acceptable internal consistency has been reported (alpha $=.78)$ (Zauszniewski, 1995). Construct validity for the DCS was demonstrated by significant correlations in the expected directions $(p<.001)$ with measures of depression, resourcefulness, adaptive functioning, and life satisfaction ( $r=.54,-.37,-.60,-.57$, respectively) (Zauszniewski, 1997a). In addition, factor analysis indicated that the DCS was unidimensional and explained $40 \%$ and $51 \%$ of the total variance of the scale in two studies (Zauszniewski, 1997a; Zauszniewski, Chung, Krafcik, \& Sousa, 2001). 


\section{Methods}

\section{Sample}

The sample included a convenience sample of 170 adolescent first-year nursing students aged 17 to 20 years old (representing late adolescence), who were admitted to Faculty of Nursing, Alexandria University, Alexandria, Egypt. Of the sample, 95.3\% of students' ages ranged between 17-19 years (Mean $=18$ years). There were 121 females $(71 \%)$ and 49 males (29\%). Approximately $37.6 \%$ of the students' fathers had college education, $34.7 \%$ had high school or technical education (2 years after high school), $24 \%$ had less than high school education, and only $3.5 \%$ had graduate/professional education. On the other hand, $25.3 \%$ of the students' mothers had college education, 35.9\% had high school or technical education (2 years after high school), $36.5 \%$ had less than high school education, and $2.4 \%$ had graduate/professional education. The number of siblings ranged from 0 to 8 with a mean of 3 ; $51 \%$ of the sample reported 6 or more family members. In relation to each student's birth order, $30 \%$ were the second child, $28 \%$ were the first child, and $18 \%$ were the last child. Regarding each student's birth order in relation to the same gender, $34.7 \%$ reported being the first child of that gender, and $31 \%$ were the second child born of that gender in the family. Further details concerning the parent study from which data used for this analysis were obtained have been reported elsewhere (Bekhet et al., in press). Based on the recommendation of at least 5-10 subjects per item of an instrument (Hair, Anderson, Tatham, \& Black, 1998; Nunnally \& Bernstein, 1994; Stevens, 2002), the sample size of 170 subjects was sufficient to conduct factor analysis of the 8-item DCS.

\section{Instruments}

A demographic questionnaire was developed by the researchers to measure individual characteristics, including age, gender, parents' education, number of siblings, number of family members, student's birth order, parents' presence in the family, student's relationship with the parents, and family problems. Besides the demographic questionnaire, the Afaf Mohamed Abd El Monem Scale (AMAS; Abd El Monem, 1988) for the feeling of alienation was used to further determine the construct validity of the Arabic version of the DCS.

\section{Alienation and Depression}

Alienation is an experience of dissatisfaction and disconnectedness with oneself, with others, with one's God, with nature, or with a transcendent realm of being. It is a sense of homelessness (Younger, 1995). Alienation is a subjective state, a feeling of being stranger as if one is not one's normal self (Schabracq \& Cooper, 2003). It is the individual's feeling of 
uneasiness or discomfort, which reflects his exclusion or self-exclusion from social or cultural participation (Levett-Jones, Lathlean, McMillan, \& Higgins, 2007). Alienation is related to the extent to which one's values, beliefs, and norms articulate with those of the particular group with which one is associated (Levett-Jones et al., 2007). In a recent study with a sample of 5,205 adolescents, Rayce, Holstein, and Kreiner (2009) found a significant association between aspects of alienation and high symptom load (experiencing at least one physical/psychological symptom on a daily basis). Kramer (2000) pointed out that "Alienation of any type might go together with depression" (p. 16). Furthermore, it has been found that isolated youth report more shyness, greater feelings of alienation, and more depression when compared with their peers (Tani, Chavez, \& Deffenbacher, 2001), suggesting that "alienation goes together with depression." Furthermore, a study conducted by Exline, Yali, and Sanderson (2000) aimed at assessing the associations between religious variables and psychological distress in a sample of 200 college students and a clinical sample of 54 persons seeking out patient psychotherapy. Results showed that feelings of alienation from God were strongly associated with depression, particularly in the clinical sample $(r=.48, p<.001)$ (Exline et al., 2000). Findings also indicated that greater social alienation increases the vulnerability to depression in a sample of 226 midlife women from the former Soviet Union (Miller et al., 2006).

Alienation was measured by the Afaf Mohamed Abd El Monem Scale (1988) for the feeling of alienation. It is reliable, valid, and has been tested with the Egyptian population previously (Abd El Monem, 1988; Bekhet, Abd El-Dayem, Naguib, \& ElGuenidi, 2005). Reliability of AMAS among the Egyptian population ranged from .76 to .89 (Abd El Monem, 1988; Bekhet et al., 2005; Bekhet et al., in press). Construct validity was demonstrated by significant correlations in the expected directions $(p<.001)$ with measures of adaptive functioning, social withdrawal, creative thinking, and depression among the Egyptian population ( $r=-.54, .57,-.60, .57$, respectively; Abd El Monem, 1988). The scale consists of 41 items on a 5-point Likert scale ranging from strongly agree (0) to strongly disagree (4). Scores may range from 0 to 164 after reverse coding 4 items. Higher scores indicate greater alienation.

Prior to subject identification and recruitment, approval was obtained from the University Institutional Review Board (IRB) and from the faculty of nursing to conduct the parent study from which this secondary analysis was obtained.

\section{Data Analysis}

Descriptive statistics were used to examine the demographics and main study variables as appropriate for the level of the variable whether categorical or continuous. Psychometric 
analysis consisted of computing Cronbach's alpha coefficient, interitem correlations, and itemto-total correlations to determine the internal consistency and homogeneity of the Arabic version of the DCS. Factor analysis was conducted to assess scale dimensionality and construct validity. Additionally, the correlation between the total scores on the Arabic version of the DCS and Afaf Mohamed Abd El Monem Scale (AMAS; 1988) for the feeling of alienation examined for convergent validity, a type of construct validity.

\section{Results}

\section{Characteristics of the Main Study Variables}

The Arabic version of the DCS's scores ranged from 0 to $40(M=12.04, S D=7.87)$, with skewness and kurtosis of 1.01 and .93 , respectively. The AMAS's feelings of alienation scores ranged from 12 to $129(M=57.13, S D=22.59)$, with skewness and kurtosis of .60 and .18 , respectively.

\section{Content/Face Validity of the Measure}

The process of translation starts with a fluent bilingual individual translating the English version of the DCS into an Arabic version. As recommended in the literature, the bilingual expert was able to make recommendations for altering the original items to make them more meaningful in the Arabic language (Brislin, 1986; Yu, Lee, \& Woo, 2004). Following the translation of the measure, a blind back-translation was completed, during which two other bilingual experts converted the translated instrument into the original English language without having seen the original instrument (Brislin, 1986; Yu et al., 2004). Discrepancies between the original and translated instruments were then examined, and decisions were made about the equivalence of the two forms. As necessary, revisions were made in the translated Arabic measure until the two forms appeared to be equivalent, which is considered to be the most reliable method in determining cultural equivalence of an instrument. Literature has suggested that when both language versions of an instrument are identical in meaning, they are more likely to be equivalent (Jones \& Kay, 1992; McDermott \& Palchanes, 1994; Yu et al., 2004).

A panel of three Arabic bilingual professionals (two nursing faculty members and one medical doctor [MD]) reviewed the consistency of the translations, grammar, and structure of the Arabic language. This panel compared the English and the Arabic versions, examining item by item. After reaching a consensus in relation to the consistency of the translations and backtranslations of the scale, as well as corrections of the Arabic language grammar and structure, an Arabic version of the DCS was produced.

\section{Cross-Cultural Equivalence Analysis}

\section{Bekhet \& Zauszniewski}


Examination of the symmetrical translations and back-translations of the DCS revealed that there was inconsistency on the scale item measuring powerlessness. One translator translated the item, "I am in control of my life" into "يمكنى التخكم في حياتى" and a second translator into " Back translations of this item were "I can control my life" and "I am in control of my life."

The panel of three Arabic bilingual members compared the original scale and two translated versions into Arabic to validate the translation. The Arabic version of the scale that Arabic panel members agreed as the one with best semantic equivalence was further reviewed and edited to meet the requirements of Arabic grammar and structure. The final item on powerlessness became "Lip"

\section{Internal Consistency and Homogeneity}

The overall estimate of the reliability of the DCS (Cronbach's alpha) was .86. This reliability estimate exceeded the recommended criterion for internal consistency of at least .70 for a newly developed scale (Nunnally \& Bernstein, 1994). Deletion of any one of the items did not improve the overall Cronbach's alpha coefficient for the scale; the coefficient of reliability continued to be very close or equal to the Cronbach's alpha reported. As shown in Tables 1 and 2, all interitem correlations and item-to-total score correlations were between $r=.30$ and $r=.70$, meeting the necessary criteria for scale internal consistency (Nunnally \& Bernstein, 1994) and homogeneity (Ferketich, 1991), respectively.

\section{Dimensionality and Construct Validity}

The Kaiser-Meyer-Olkin value of .88 also indicated that the sample size was adequate for the purpose of proceeding with factor analysis because it exceeded the recommended value of .60 (Tabachnick \& Fidell, 2001).

A principal components factor analysis was conducted on the Arabic version of the DCS's items to extract the minimum number of factors that explained the maximum variance in the items of the scale. As shown in previous studies conducted by Zauszniewski (1997a) and Zauszniewski and colleagues (2001), it was expected in this study that only one factor would emerge from factor analysis. In fact, the factor extraction generated only one factor with eigenvalue greater than 1 . The scree plot also clearly suggested that only one dimension underlay the items of the scale. As shown in Table 1, a single extracted factor explained $49.95 \%$ of the variance in the items of the scale. Thus, factor rotation was not needed. All communality values were above .30, as recommended by Tabachnick and Fidell (2001), and all items of the 
scale had strong factor loadings on the single factor that emerged, exceeding the minimum recommended criterion of .30 (Nunnally \& Bernstein, 1994; Polit, 1996).

The Arabic version of the DCS's total score had a strong positive correlation with the total score of the Alienation Scale scores $(r=.51, p<.01)$, thereby suggesting construct validity.

\section{Discussion}

This study represents the first attempt to examine the reliability and the validity of an Arabic version of the 8-item Depressive Cognition Scale (DCS). The results provide solid support for the scale's reliability and validity among first-year nursing students. Reliability was demonstrated through adequate estimates of internal consistency; Cronbach's alpha was .86, which exceeds the minimum criterion of .70 (Nunnally \& Bernstein, 1994). This internal consistency estimate is consistent with findings from other studies of DCS measures, which reported alpha of .78 in a sample of older adults (Zauszniewski, 1995); alphas of .75 and .87, respectively, in African American female caregivers and noncaregivers (Zauszniewski, Picot, Debanne, Roberts, \& Wykle, 2002); and an alpha of .85 in women with type 2 diabetes (Zauszniewski et al., 2001). The corrected item-to-total correlations for all 8 items exceeded the .30 criterion (Cronk, 2004), suggesting the homogeneity of the measure and that each item was measuring a unique construct. This finding is also consistent with findings from studies of the measure of the DCS in Brazilian adults of diabetes mellitus (Sousa, Zanetti, Zauszniewski, Mendes, \& Daguano, 2008), healthy American elders (Zauszniewski, 1997a, 1997b), and American women with type 2 diabetes (Zauszniewski et al., 2001).

In addition to providing evidence of the reliability of the Arabic version of the DCS, the findings indicate that the measure has construct validity, as evidenced by significant correlations of $.51(p<.01)$ in the expected direction with an established measure of alienation. The findings of this study are consistent with the findings with previous studies, which found a significant positive correlation between the DCS and alienation in a sample of 204 male and 208 female students selected randomly in high schools (Lee, 2007).

The findings of the factor analysis provide further support for the construct validity of the DCS. The emergence of a single factor that explained a substantial portion of the variance is consistent with factor analytic studies of the DCS (Sousa et al., 2008; Zauszniewski, 1997a; Zauszniewski et al., 2001). The variance explained in this study (49.95\%) is similar to some extent to the variance explained in the study of African American women, noncaregivers (46\%) (Zauszniewski et al., 2002) and less than the variance explained in the study of Brazilian adults with diabetes mellitus (56.73\%) (Sousa et al., 2008). However, it should be noted that the 
population is different in this study than the two mentioned studies. The greater amount of variance may be due to the fact that first-year nursing students constitute a more homogeneous population.

The findings from this analysis of the psychometric properties of the Arabic version of the DCS in first-year nursing students yield promising evidence that the 8-item DCS has acceptable reliability and validity. The findings also indicate that the DCS is potentially useful for assessing depressive cognitions that precede the development of clinical depression for firstyear nursing students, which is important for early intervention and prevention of depression in adolescent nursing students.

Further psychometric testing of the scale may be warranted. This study provides evidence that the DCS consists of a single dimension and supports the construct validity of the DCS for this sample of first-year Egyptian nursing students.

\section{Notes}

- Correspondence regarding this article should be directed to Abir K. Bekhet, PhD, RN, HSMI, Assistant Professor, College of Nursing, Marquette University, Clark Hall, 530 N. 16th Street, Milwaukee, WI 53233. E-mail: abir.bekhet@marquette.edu

\section{References}

Abd El Monem, A. M. (1988). Alienation and psychological changes among normal and blind university students. Unpublished doctoral dissertation, Alexandria University, Egypt.

Afifi, M. (2006). Adolescent suicide in the Middle East: Ostrich head in sand. Bulletin of the World Health Organization, 84 (10), 840.

Ahmadi, J. (1994a). Rate of depression among medical students, resident physicians and physiotherapy students at Shiraz University of Medical Sciences. Shiraz University Journal of Social Sciences and Humanities, 10, 101-111.

Ahmadi, J. (1994b). Rate of depression among students at Shiraz University. Journal of Students and Research, 2, 2-4.

Ahmadi, J., Toobaee, S., \& Alishahi, M. (2004). Depression in nursing students. Journal of Clinical Nursing, 13(1), 124.

Badamgarav, E., Weingarten, S. R., Henning, J. M., Knight, K., Hasselblad, V., Gano, J. R., et al., (2003). Effectiveness of disease management programs in depression: A systematic review. The American Journal of Psychiatry, 160, 2080-2090. 
Beck, A. T., Ward, C. H., Mendelson, M., Mook, J., \& Erbaugh, J. (1961). An inventory for measuring depression. Archives of General Psychiatry, 4, 561-571.

Bekhet, A., Abd El-Dayem, S., Naguib, M., \& ElGuenidi, M. (April, 2005). Alienation among diploma nursing school students in Alexandria (abstract). Proceedings from the 7th Annual Conference of the International Society for Psychiatric-Mental Health Nurses (ISPN). Pittsburgh, Pennsylvania.

Bekhet, A., ElGuenidi, M., \& Zauszniewski, J. A. (in press). The effects of positive cognitions on the relationship between alienation and resourcefulness in nursing students in Egypt. Issues in Mental Health Nursing.

Bertolote, J. M., Fleischmann, A., Butchart, A., \& Besbelli, N. (2006). Suicide, suicide attempts, and pesticides: A major hidden public health problem. Bulletin of the World Health Organization, 84 (10), 260.

Brislin, R. W. (1986). The wording and translation of research instruments. In W. J. Lonner \& J. Berry (Eds.), Field methods in cross-cultural research (pp. 137-164). Beverly Hills, CA: Sage Publications.

Carlson, G. A. (2000). The challenge of diagnosing depression in childhood and adolescence. Journal of Affective Disorder, 61 (1), 3-8.

Cashman, S. B., Hale, J., Candib, L. M., Nimiroski, T. A., \& Brookings, D. R. (2004). Applying service-learning through a community-academic partnership: Depression screening at a federally funded community health center. Education for Health, 17 (3), 313-322.

Castiglia, P. T. (2000). Depression in children. Journal of Pediatric Health Care, 14 (2), 73-75.

Cronk, B. C. (2004). How to use SPSS: A step-by-step guide to analysis and interpretation (3rd ed.). Glendale, CA: Pyrczak Publishing.

Dzurec, L. C., Allchin, L., \& Angler, A. J. (2007). First-year nursing students accounts of reasons for student depression. Journal of Nursing Education, 46 (12), 545-551.

Exline, J. J., Yali, A. M., \& Sanderson, W. C. (2000). Guilt, discord, and alienation: The role of religious strain in depression and suicidality. Journal of Clinical Psychology, 56 (12), 1481-1496.

Ferketich, S. (1991). Aspects of item analysis. Research in Nursing and Health, 14 (2), 165-168. Hair, J.F.J., Anderson, R. E., Tatham, R. L., \& Black, W. C. (1998). Multivariate data analysis ( $5^{\text {th }}$ ed.). Englewood Cliffs, NJ: Prentice Hall.

Halter, M. J. (2004). Stigma \& help seeking related to depression: A study of nursing students. Journal of Psychosocial Nursing, 42 (2), 42-54. 
Hamilton, M. (1960). A rating scale for depression. Journal of Neurology, Neurosurgery, and Psychiatry, 23, 56-58.

Jones, E. G., \& Kay, M. (1992). Instrumentation in cross-cultural research. Nursing Research, 41 (3), 186-188.

Kloos, A. L., Collins, R., Weller, R. A., \& Weller, E. B. (2007). Suicide in preadolescents: Who is at risk? Current Psychiatry Reports, 9 (2), 89-93.

Kramer, P. D. (2000). The valorization of sadness: Alienation and the melancholic temperament. Hastings Center Report, 30 (2), 13-18.

Lee, E. (2007). Construction of a structural model about male and female adolescents' alienation, depression, and suicidal thoughts [Abstract]. Taehan Kanho Hakhoe Chi, 37 (4), 576-585.

Levett-Jones, T., Lathlean, J., McMillan, M., \& Higgins, I. (2007). Belongingness: A montage of nursing students' stories of their clinical placement experiences. Contemporary Nurse, 24 (2), 162-174.

Louters, L. L. (2006). Don't overlook childhood depression. Journal of the American Academy of Physician's Assistants, 17, 18-24.

Lustman, P. J., Clouse, R. E., \& Carney, R. M. (1988). Depression and the reporting of diabetes symptoms. International Journal of Psychiatry in Medicine, 18 (4), 295-303.

Lustman, P. J., Freedland, K. E., Carney, R. M., Hong, B. A., \& Clouse, R. E. (1992). Similarity of depression in diabetic and psychiatric patients. Psychosomatic Medicine, 54 (5), $602-$ 611.

Lustman, P. J., Griffith, L. S., Gavard, J. G., \& Clouse, R. E. (1992). Depression in adults with diabetes. Diabetes Care, 15 (11), 1631-1639.

McDermott, M.A.N., \& Palchanes, K. (1994). A literature review of the critical elements in translation theory. Image: Journal of Nursing Scholarship, 26 (2), 113-117.

Miller, A. M., Sorokin, O., Wang, E., Feetham, S., Choi, M., \& Wilbur, J. (2006). Acculturation, social alienation, and depressed mood in midlife women from the Former Soviet Union. Research in Nursing and Health, 29, 134-146.

Müller, M. E., \& Dzurec, L. C. (1993). The power of the name. Advances in Nursing Science, 15 (3), 15-22.

Nunnally, J. C., \& Bernstein, I. H. (1994). Psychometric theory (3rd ed.). New York: McGraw-Hill. Polit, D. F. (1996). Data analysis and statistics for nursing research. Stamford, CT: Appleton \& Lange. 
Rayce, S. L., Holstein, B. E., \& Kreiner, S. (2009). Aspects of alienation and symptom load among adolescents. European Journal of Public Health, 19(1), 79-84.

Sax, L. J., Bryant, A. N., \& Gilmartin, S. K. (2002, November). A longitudinal investigation of emotional health among first-year students: Comparisons of men and women. Paper presented at the annual meeting of the Association for the Study of Higher Education, Sacramento, CA.

Schabracq, M., \& Cooper, C. (2003). To be me or not to be me: About alienation. Counseling Psychology Quarterly, 16 (2), 53-79.

Son, S. E., \& Kirchner, J. T. (2000). Depression in children and adolescents. American Family Physician, 62 (10), 2297-2308.

Sousa, V. D., Zanetti, M. L., Zauszniewski, J. A., Mendes, I. A., \& Daguano, M. O. (2008). Psychometric properties of the Portuguese version of the Depressive Cognition Scale in Brazilian adults with diabetes mellitus. Journal of Nursing Measurement, 16 (2), 125-135.

Sousa, V. D., Zauszniewski, J. A., Mendes, I. A., \& Zanetti, M. L. (2005). Cross-cultural equivalence and psychometric properties of the Portuguese version of the depressive cognition scale. Journal of Nursing Measurement, 13 (2), 87-99.

Stevens, J. (2002). Applied multivariate statistics for the social sciences (4th ed.). Mahwah, NJ: Lawrence Erlbaum Associates.

Tabachnick, B. G., \& Fidell, L. S. (2001). Using multivariate statistics (4th ed.). Needham Heights, MA: Allyn \& Bacon.

Tani, C. R., Chavez, E. L., \& Deffenbacher, J. L. (2001). Peer isolation and drug use among white non-Hispanic and Mexican American adolescents. Adolescence, 36 (141), $127-$ 138.

Weissman, M. M., Sholomskas, D., Pottenger, M., Prusoft, B. A., \& Locke, B. Z. (1977). Assessing depressive symptoms in five psychiatric populations: A validation study. American Journal of Epidemiology, 106, 203-212.

Younger, J. (1995). The alienation of the sufferer. Advances in Nursing Science, 17 (4), 57-59.

Yu, D.S.F., Lee, D.T.E, \& Woo, J. (2004). Issues and challenges of instrument translation. Western Journal of Nursing Research, 26 (3), 307-320.

Zauszniewski, J. A. (1995). Development and testing of a measure of depressive cognition in older adults. Journal of Nursing Measurement, 3 (1), 31-41.

Zauszniewski, J. A. (1997a). The Depressive Cognition Scale: Further psychometric evaluation. Journal of Nursing Measurement, 5 (2), 191-200. 
Zauszniewski, J. A. (1997b). Evaluation of measure of learned resourcefulness for elders. Journal of Nursing Measurement, 5 (1), 71-86.

Zauszniewski, J. A., Chung, C., Krafcik, K., \& Sousa, V. (2001). Psychometric testing of the Depressive Cognition Scale in women with type 2 diabetes. Journal of Nursing Measurement, 9 (1), 61-72.

Zauszniewski, J. A., Picot, S. J., Debanne, S. M., Roberts, B. L., \& Wykle, M. L. (2002).

Psychometric characteristics of the Depressive Cognition Scale in African American women. Journal of Nursing Measurement, 10 (2), 83-95.

Zung, W.W.K. (1965). A self rating depression scale. Archives of General Psychiatry, 12, 63-68.

\section{Appendix}

Table 1

The Arabic Version of the DCS Item Analysis and Factor Analysis $(N=170)$

\begin{tabular}{lcccc} 
Item & $\begin{array}{c}\text { Alpha if } \\
\text { Item Deleted }\end{array}$ & $\begin{array}{c}\text { Item-to-Total } \\
\text { Score Correlation }\end{array}$ & $\begin{array}{c}\text { Factor } \\
\text { Loadings }\end{array}$ & $\begin{array}{c}\text { Communality } \\
\text { Values }\end{array}$ \\
\hline Emptiness & .84 & .53 & .64 & .41 \\
Helplessness & .85 & .51 & .62 & .38 \\
Hopelessness & .84 & .61 & .72 & .52 \\
Loneliness & .84 & .58 & .69 & .48 \\
Meaninglessness & .83 & .62 & .72 & .52 \\
Powerlessness & .84 & .59 & .70 & .49 \\
Purposelessness & .83 & .65 & .76 & .58 \\
Worthlessness & .83 & .69 & .79 & .62 \\
Eigenvalue & & & 3.99 & \\
\% Variance explained & & & 49.95 & \\
Factor Cronbach's alpha & & & .86 &
\end{tabular}




\section{Table 2}

The Arabic Version of the DCS Interitem Correlation Matrix $(N=82)$

\begin{tabular}{|c|c|c|c|c|c|c|c|c|}
\hline Item & 1 & 2 & 3 & 4 & 5 & 6 & 7 & 8 \\
\hline 1. Emptiness & 1 & 1 & & & & & & \\
\hline 2. Helplessness & $.37^{*}$ & 1 & & & & & & \\
\hline 3. Hopelessness & $.44^{*}$ & $.40^{*}$ & 1 & & & & & \\
\hline 4. Loneliness & $.32 *$ & $.33 *$ & $.47^{*}$ & 1 & & & & \\
\hline 5. Meaninglessness & $.45^{*}$ & $.31 *$ & $.42 *$ & $.52 *$ & 1 & & & \\
\hline 6. Powerlessness & $.36^{*}$ & $.34 *$ & $.40^{*}$ & $.41^{*}$ & $.45^{*}$ & 1 & & \\
\hline 7. Purposelessness & $.36^{*}$ & $.39 *$ & $.44^{*}$ & $.46^{*}$ & $.46^{*}$ & $.45^{*}$ & 1 & \\
\hline 8. Worthlessness & $.40^{*}$ & $.44 *$ & $.49^{*}$ & $.40^{*}$ & $.45^{*}$ & $.53 *$ & $.69^{*}$ & 1 \\
\hline
\end{tabular}

${ }^{*} p<.001$ 